\title{
Alteraciones inmunológicas en la desnutrición
}

\author{
DRA. LIANA SCHLESINGER * Y DR. ABRAHAM S'TEKEL *
}

Tanto la experiencia clinica, como la experimental señalan que la desnutrición y la infección se entrelazan intimamente potenciando sus efectos en forma recíproca $(1,2)$. Es así como en la desnutrición aumenta la incidencia y gravedad de las infecciones y estas últimas al repetirse agravan la desnutrición, determinándose un círculo difícil de quebrar. Infecciones que son banales en el sujeto eutrófico constituyen, en cambio, un alto riesgo de morir en aquellas zonas en que la desnutrición es prevalente.

Este sinergismo produce los mayores estragos en los primeros años de la vida. En Latino América la mortalidad infantil en muchas regiones es superior a 80 y la mortalidad entre 1 y 4 años de edad es diez a treinta veces mayor que en los países desarrollados (3).

A pesar de la clara interacción entre desnutrición o infección, Ia primera no aparece lo suficientemente destacada como causa de muerte. En los índices de mortalidad en Chile, por ejemplo, durante 1964 aparecen 4.661 niños fallecidos por diarrea aguda (4), siendo lo probable que la causa subyacente haya sido la desnutrición previa y la diarrea sólo una complicación final. En la experiencia de Monckeberg y cols. la deshidratación grave por diarrea tiene una mortalidad aproximadamente del $30 \%$ en niños pequeños desnutridos mientras que sólo alcanza al $6 \%$ en el normal (5). Algo semejante ocurre con el sarampión y la tuberculosis $(6,7)$.

Los mecanismos mediante los cuales la infección agrava la desnutrición son probablemente múltiples y poco conocidos. Muchas infecciones, por ejemplo, determinan anorexia y producen una

\footnotetext{
* Meartamento de Uutrición y Tecnología de Jos Alimentos. Sede Santíago Sur. Universidad de Chile.

* Financiado en parte por Grant N. I. H. HDO 3741-12 USA. y por Grant de la Eundación Ford.
}

alteración metabólica que se manifiesta por un balance nitrogenado negativo. Los mecanismos por los que la desnutrición aumenta la incidencia y gravedad de las infecciones han comenzado a aclararse en los últimos años.

La mayor frecuencia de las infecciones podría ser consecuencia de las malas condiciones socioeconómicas y el hacinamiento en que estos sujetos habitan; su mayor severidad, sin embargo está seguramente condicionada por una alteración de los mecanismos defensivos, los cuales analizaremos en detalle en este artículo.

\section{MECANISMOS DEFENSIVOS DEL HUESPED NORMAL}

El ser humano normal al ser agredido por un agente infectante responde haciendo uso de sus mecanismos defensivos. Estos mecanismos son básicamente de 2 tipos:

a) Inespecíficos, entre los cuales se cuentan las barreras epiteliales y mucosas, factores como la lisozima y la properdina, la respuesta inflamatoria y la fagocitosis, $y$

b) Especificicos: representados por el aparato inmunológico que se encuentra claramente definido $y$ que se caracteriza por responder en forma específica frente a cada agente agresor y por guardar memoria de su respuesta. Al ser estimulado, el aparato inmunológico responde secretando inmunoblobulinas $o$ anticuerpos (respuesta humoral) o mediante la formación de linfocitos pequeños sensibilizados (respuesta celular).

El aparato inmunológico en el ser humano se encuentra representado por 2 6rganos centrales, 


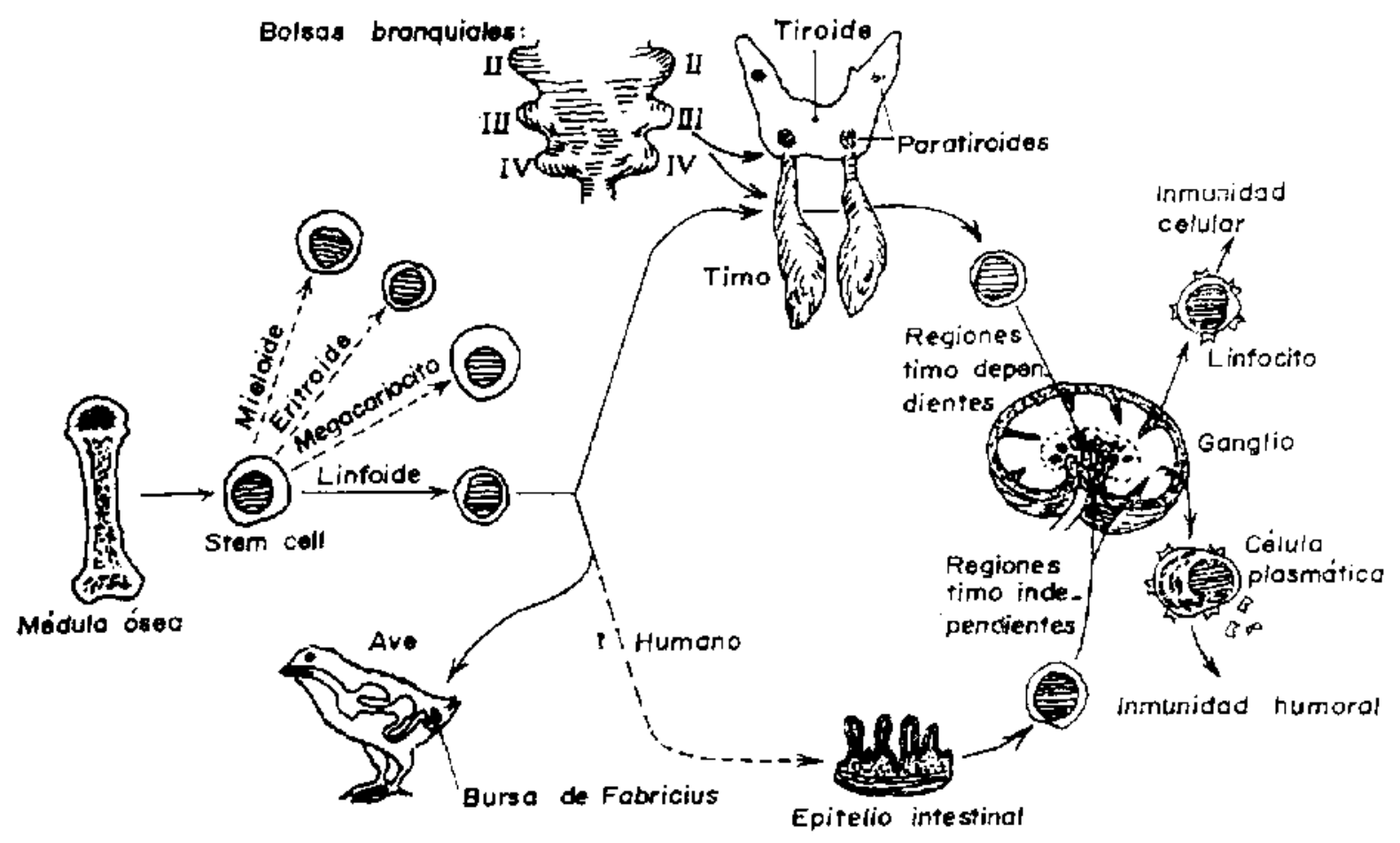

REPRESENTACION ESQUEMATICA DE LA ONTOGENIA DE la REsPuesta iniane ."

el timo y un equivalente no precisado de la Bursa de Fabricius de las aves, y por órganos periféricos constituidos por los ganglios linfáticos el bazo, el apéndice, las ámígdalas y las placas de Peyer. Este sistema se origina durante la vida intrauterina por la colonización de los esbozos embrionarios de los órganos centrales por células inmaduras provenientes de la médula ósea que posteriormente dan origen a las células inmunocompetentes que van a poblar los tejidos linfáticos periféricos. Estas células inmunocompeteentes se van a ubicar en áreas bien específicas constituyendo las zonas timodependientes (formadas por células $\mathrm{T}$ ) y las áreas timo independientes (formadas por células B). Las células inmunocompetentes (linfocitos pequeños). ya sean $\mathbf{T}$ o $\mathbf{B}$, al entrar en contacto con una sustancia antigénica se transforman en elementos inmaduros, inmunoblastos, que proliferan dando origen ya sea a una célula plasmática que secreta inmunoglobulinas, en el caso de que se esté evocando una respuesta humoral, o a un linfocito pequeño sensibilizado si se trata de un antígeno que induzca una respuestit de lipo celular. (Fig. 1).

La jmportancia de estas dos poblaciones celu-
- Bellonti, A A. Immunulogy Sounders, 1971

lares es enorme y actualmente se describen cuadros de inmunodeficiencias determinadas por ausencia de una o ambas líneas (8). Niños que nacen sin el sistema de células $T$ son incapaces de resistir infecciones producidas por determinados virus (rubeola, vaccinia, sarampión, etc.), ciertas bacterjas (microbacteria tuberculosa) y algunos hongos (candida albicans) (9). Estos sujetos pierden incluso in capacidad de rechazar homotransplantes. Los sujetos que nacen sin el sistema Bursa dependiente hacen infecciones frecuentes a bacterias encapsuladas como neumococo, hemofilus, streptococo, etc. (9).

\section{RESPUESTA INMUNOLOGICA EN LA DESNUTRICION}

\section{Mecanismos Inespecíficos}

La desnutrición calórico proteica grave altera la integridad tisular de la piel y las mucosas que constituyen la primera barrera defensiva con que cuenta el ser humano frente a la agresión de agentes infectantes. No sólo se altera la permeabilidad 
de estas estructuras, sino que se reduce la secreción de las mucosas y algunas de ellas pierden los cilios (ej. mucosa respiratoria) (10).

Se ha descrito también una disminución de la fisosima en estos sujetos. Dawson y Blagg probaron la actividad bactericida de la saliva de niños desnutridos y niños eutróficos contra diversos agentes microbianos y encontraron que la saliva de los primeros casi no poseía actividad antibacteriana en relación a la de los controles sanos (11).

En lo que se refiere a la actividad del complemento, Kumate ha titulado C'1, C'2, C'3 y C'4, encontrando títulos serologicos ligeramente disminuidos (12). Dado a que la disminución de los niveles de complemento es discreta (15 a $20 \%$ ), se supone que no jugaría un rol patogénico de importancia en la mayor susceptibilidad a las infecciones que presentan estos sujetos.

La reacción inflamatoria puede medirse mediante la técuica de la "ventana cutânea". Este pro. cedimiento permite conocer el tipo de leucocitos y la proporción en que se encuentran presentes durante las diferentes etapas del proceso inflamatorio. Kumate aplicó esta técnica para estudiar la respuesta inflamatoria en sujetos desnutridos. Este autor no observó diferencias significativas con respecto a los controles normales en el porcentaje de neutrófilos que se acumulaban a nivel de la ventana cutánea después de 4-6 horas (12).

La actividad fagocitaria y bactericida de los leucocitos que había sido descrita como alterada
(13), se ha encontrado normal en investigaciones recientes con técnicas más sofisticadas. (14, 15).

\section{Mecanismos Especificos}

\section{A.- Respuesta Humoral}

Numerosos autores han descrito en niños con Kwashiorkor niveles normales o elevados de inmunoglobulinas séricas $(12,16-20)$. Se ha observado que los niveles de Ig $G$ son semejantes a los de los controles, pero los títulos de Ig M e Ig A son significativamente mayores. Al recuperarse la desnutrición los niveles de Ig $\mathrm{G}$ permanecen estacionarios y los de Ig M e Ig A persisten elevados (Tabla 1). El alza de estas inmunoglobulinas podría deberse a la repetida estimulación antigénica a que se encuentran sometidos estos sujetos.

En el marasmo se ha comunicado que entre $\operatorname{los} 3$ y 6 meses de edad los niveles de Ig G, Ig M e Ig A son significativamente más elevados que en los controles eutróficos. Entre $\operatorname{los} 7$ y 12 mieses se eleva especialmente la Ig M y entre los 13 y 30 meses son significativamente mayores los niveles de Ig A (21).

Johansson encontró niveles de $\operatorname{Ig} \mathrm{D}$ e $\mathrm{Ig} \mathrm{E}$ elevados en niños etiopes en comparación con niños suecos de edades similares (22).

En lo que se refiere a la formación de anticuerpos especifficos, se han adecuado varios estu-

TABLA I ( $\left.{ }^{*}\right)$

TITULOS DE INMUNOGLOBULINAS EN EL CURSO DEL KWASHIONOR, EXPRESADAS EN MG/IOO $\mathrm{ml}$.

\begin{tabular}{|c|c|c|c|c|c|c|c|}
\hline & Autores & Browys (16) & Kumate (I2) & Keet (I7) & Watson (I8) & $\begin{array}{c}\text { Mc. Farlane } \\
\text { (19) }\end{array}$ & Zucker (20) \\
\hline \multirow{3}{*}{ Ig G } & Controles & 1.740 & 1.092 & 1.212 & 1.476 & & 1.512 \\
\hline & $\begin{array}{l}\text { Kwashiokor } \\
\text { Inicio }\end{array}$ & 1.200 & 971 & 1.335 & 3.106 & 2.312 & 1.178 \\
\hline & $\begin{array}{l}\text { Kwashiorkor } \\
\text { Recuperación }\end{array}$ & & 990 & & 1.486 & 2.183 & 1.521 \\
\hline \multirow{3}{*}{ Ig A } & Controles & 90 & 96 & 71 & 99 & & 146 \\
\hline & $\begin{array}{l}\text { Kwashiorkor } \\
\text { Inicio }\end{array}$ & 164 & 158 & 152 & $1 \overline{54}$ & 187 & 216 \\
\hline & $\begin{array}{l}\text { Kwashiorkor } \\
\text { Recuperación }\end{array}$ & & 135 & & $1 \overline{16}$ & $149^{-}$ & 218 \\
\hline \multirow{3}{*}{$\operatorname{Ig} \mathbf{M}^{\prime}$} & Controles & 124 & 89 & 150 & 120 & & 126 \\
\hline & $\begin{array}{l}\text { Kwashiorkor } \\
\text { Inicio }\end{array}$ & 101 & $12 \overline{6}$ & 152 & 93 & 126 & 118 \\
\hline & $\begin{array}{l}\text { Kwashiorkor } \\
\text { Recuperación }\end{array}$ & & 162 & & 143 & 142 & -122 \\
\hline
\end{tabular}

* Zucker, J. M. et Col. Rev. Europ. Etudes Clin et Biol 16: 1043, 1971. 
TA B L A II (*)

FORMACION DE ANTICUERPOS ESPECIFICOS EN LA DESNUTRICION

\begin{tabular}{l|l|l|l}
\hline Antigeno & \multicolumn{1}{|c|}{ Tipo de desmutición } & Respuesta & \multicolumn{1}{|c}{ Autor } \\
\hline Virus Parotiditis & Desnutrición Calórica Proteica & Deprimida & Kumate (12) \\
Virus Sarampión & Retardo Crecimiento & Normal & Mata. Datos no publicados (23) \\
Virus Influenza & Desnutrición Calórico Protejca & Deprimida & José, Datos no publicados (23) \\
Vacuna Antíf́́fica & Desnutrición Calórico Proteica & Deprimida & Budiansky et Da Silva (24) \\
Vacuna Antitífica & Kwashiorkor & Normal & Pretorius (25) \\
Toxoide Diftérico & Kwashiorkor & Deprimida & Olarte (26) \\
Fiebre Amarilla & Kwashiorkor & Deprimida & Brown-Katz (27) \\
Virus Polio & Kwashiorkor & Normal & Mc. Farlanee (19) \\
\hline
\end{tabular}

* Modificado Bull. Wld. Hirth. Org. 46: 537, 1972.

TA B L A I I I

RESPUESTA INMUNOLOGICA CELULAR EN LA DESNUTRICION

\begin{tabular}{|c|c|c|c|c|c|c|}
\hline $\begin{array}{l}\text { Tipo de des- } \\
\text { mufrición }\end{array}$ & $\begin{array}{l}\text { Edades } \\
\text { (meses) }\end{array}$ & $\begin{array}{l}\text { Sensibiliza- } \\
\text { ción con } \\
D N C B(1)\end{array}$ & $\begin{array}{c}\text { Tuberculina } \\
\text { (I) }\end{array}$ & $\begin{array}{l}\text { Otros tests cutá- } \\
\text { táneos }(1)\end{array}$ & $\begin{array}{l}\text { Transformacion } \\
\text { Biastica con PHA }\end{array}$ & Autor \\
\hline DCP & $3 \mathrm{~m}-72 \mathrm{~m}$ & $5 / 17$ & & & $\downarrow$ & $\begin{array}{l}\text { Smythe y } \\
\text { Col (35) }\end{array}$ \\
\hline $\mathbf{K w}$ & $6 \mathrm{~m}-30 \mathrm{~m}$ & & & $\begin{array}{l}\text { Candida } 3 / 18 \\
\text { Difteria } 4 / 18\end{array}$ & $\downarrow$ & $\begin{array}{l}\text { Geffhuysen y } \\
\text { Col. (40) }\end{array}$ \\
\hline $\begin{array}{l}\text { DCP severa } \\
\text { DCP moderada }\end{array}$ & $\begin{array}{l}2 \mathrm{~m}-68 \mathrm{~m} \\
2 \mathrm{~m}-68 \mathrm{~m}\end{array}$ & $\begin{array}{l}0 / 3 \\
1 / 3\end{array}$ & $2 / 17$ & $\begin{array}{l}\text { Candida } 0 / 5 \\
\text { Candida } 2 / 6\end{array}$ & & $\begin{array}{l}\text { Faldman y } \\
\text { Col. (38) }\end{array}$ \\
\hline DCP & $12 \mathrm{~m}-60 \mathrm{~m}$ & $8 / 23$ & $9 / 50$ & $\begin{array}{l}\text { Candida } 4 / 30 \\
\text { Streptokina- } \\
\text { sa } 5 / 30 \\
\text { Tricofitina } 2 / 30\end{array}$ & $\downarrow$ & Chandra (37) \\
\hline$M y \mathrm{Kw}$ & $12 \mathrm{~m}-60 \mathrm{~m}$ & $\begin{array}{r}3 / 15(2) \\
7 / 8(3)\end{array}$ & & Candida $2 / 14$ & & Edelman (39) \\
\hline $\mathbf{M}$ & $3 m-18 m$ & $\begin{array}{l}1 / 9(4) \\
3 / 3(5)\end{array}$ & $1 / 12$ & & $\mathbf{N}$ & $\begin{array}{l}\text { Schlesinger y } \\
\text { Col. (36) }\end{array}$ \\
\hline
\end{tabular}

(1) Se expresa como $\mathrm{N}^{9}$ de casos con respuesta positiva $/ \mathrm{N}^{\circ}$ total de casos.

(2) Primer contacto con el DNCB entre el 19 y $15 \%$ dia de ingreso.

(3) Primer contacto con el DNCB a los 56 dias de ingreso.

(4) Primer contacto con el DNCB entre el $10^{\circ}$ y $30^{\circ}$ día de ingreso.

(5) Primer contacto con el DNCB después del 30\% dia de ingreso.

DCP Desnutrición Calórico-Proteica.

Kw Kwashiorkor.

M Matasmo.

dios cuyos resultados son contradictorios $(12,19$, 23-27) (Tabla II).

Esto puede deberse a que en estos estudios no siempre se ha definido $y$ estandarizado el antígeno cmpleado ni la etapa en la cual se ha estudiado al nino desnutrido. Es interesante la observación de que a pesar de poseer niveles elevados de inmunoglobulinas, los sujetos desnutridos responden en algunos casos formando menor cantidad de anticuerpos frente a estímulos antigénicos específicos. 
GANGLIO

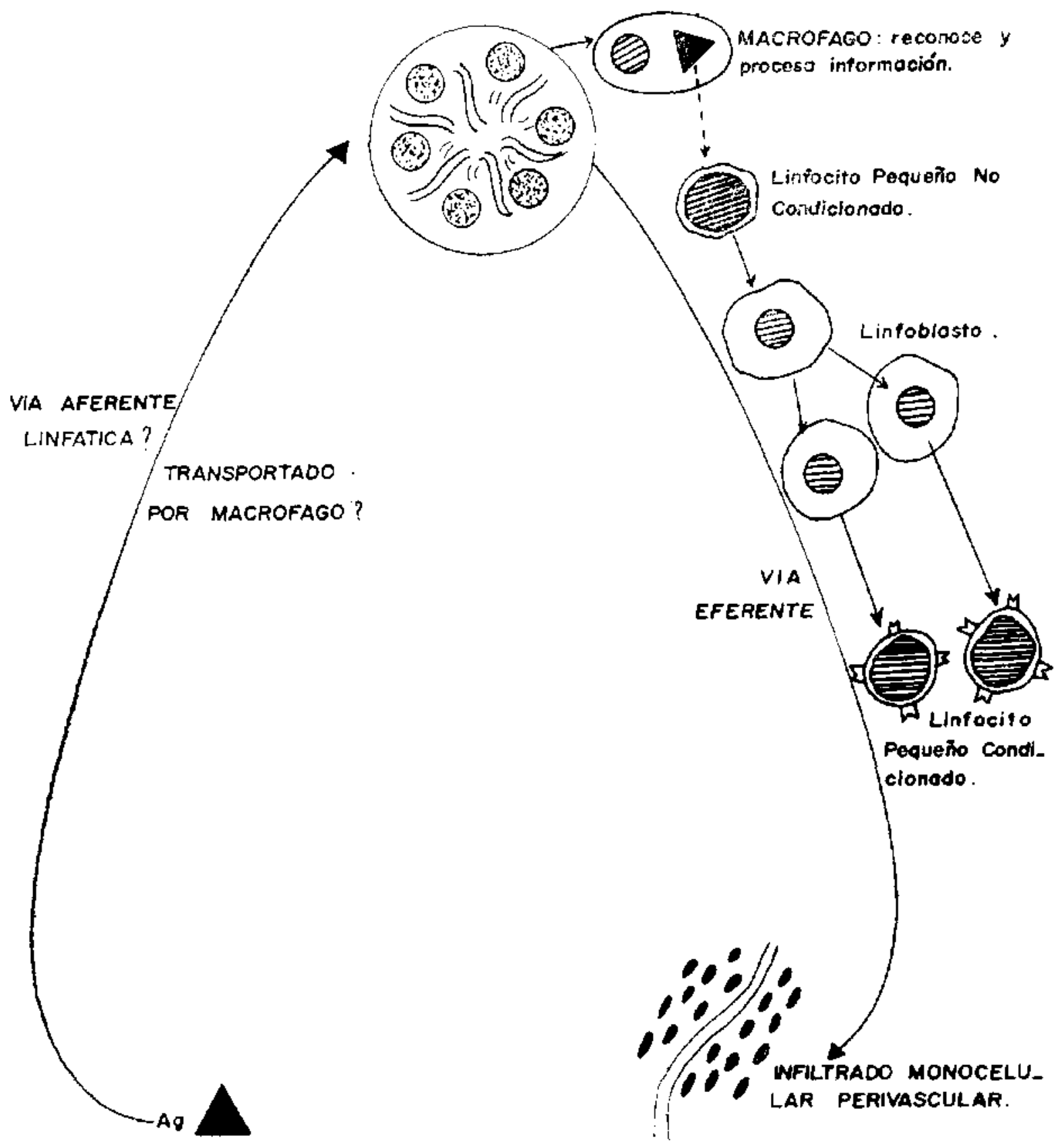

\section{B._- Respuesta Celular.}

Este mecanismo defensivo ha comenzado a es. tudiarse más recienternente. Lo primero que llamó la atención fue la alta proporción de reacciones tuberculínicas negativas en sujetos desnutridos con respecto a los controles normales $(28-30)$. Se recordó también que ya en 1937 Vint había descri- 
to atrofia del timo en niños que fullecieron con Kwashiorkor, (31) observación que posteriormente fue confirmada por otros autores $(32,33)$. Se ha observado además en cstos nitos una mayo" frecuencia de infecciones virales como herpes simple y sarampión, enfermedades que se asocian a defectos de la respuesta inmunitaria celular (2, 34).

A la luz de los hechos, muchos investigadores comenzaron a pensar que probablemente la gravedad de las infecciones en los sujetos desnutridos podría explicarse por una alteración de las células $T y$ se dedicaron a investigar el comportamiento de la respuesta inmunológica celular. Algunos de estos estudios se resumen en la Tabla III.

En autopsias practicadas en niños fallecidos por desnutrición severa se ha confirmado una marcada atrofia del sistema timolinfático (31-33). En un reciente artículo de revisión, se citan observaciones no publicadas de Marigó en que se describe depleción parcial o completa de los linfocitos de la zona cortical del timo con aumento de la fibrosis intersticial y relativamente pocos cambios en la médula. En los ganglios linfáticos Marigó observó depleción de las áreas paracorticales que representan las zonas timodependientes (23). Hallazgos similares han sido descritos por Smythe y cols. (35).

Nosotros, que bemos estado estudiando en los últimos años la respuesta inmunitaria celular en la desnutrición marásmica severa (36), hemos comprobado que la mayoría de los lactantes marásmicos son incapaces de sensibilizarse con Dinitroclorobenceno (DNCB). Esta reacción persiste negativa una vez recuperada la desnutrición. Este fenomeno ha sido observado por otros autores $(35,73,38,39)$. Junto a esto se ha encontrado un número significativamente más alto de reacciones cutáneas regativas frente a antígenos que evocan respuesta celular como candidina, difteria, streptoquinasa y tricofitina $(35,37-40)$.

La capacidad proliferativa de los linfocitos fue estudiada en nuestros pacientes marásmicos, midiendo la capacidad de transformación blástica de los linfocitos in vitro estimulados con firohemaglobulina (P. H. A.) (36). Encontramos valores de transformación normales, hecho que concuerda con las observaciones de López y cols. en animales de experimentación (41). En cambio en el Kwashiorkor la capacidad proliferativa de los linfocitos estaría disminuido $(35,37,40)$. Esta discrepancia puede deberse a las diferencias que existen entre Kwashiorkor y Marasmo (42).

De lo anteriormente expuesto se puede concluir que en los sujetos desnutridos existen alteraciones de numerosos mecanismos defensivos. La principal alteración descrita hasta el momento es probablemente la de la respuesta inmunitaria celular, sin embargo, no se ha determinado en que etapa de esta respuesta se encontraría el defecto.

La existencia de respuesta normal a la P.H.A. en nuestros pacientes parece indicar que a pesar le la severa atrofia del timo, persisten células $T$ con capacidad proliferativa normal en los sujetos marásmicos. Además, los línfocitos de niños desnutridos serían capaces de producir algunos mediadores químicos como lo indica el hecho de que se puede transferir pasivamente a estos sujetos la capacidad de reaccionar a la tuberculina mediante la inyección de linfocitos sensibilizados provenientes de sujetos tuberculinos positivos (43). Este hecho demostraría de paso, la existencia de una respuesta inflamatoria adecuada.

La Figura II representa en forma esquemática la respuesta inmunológica celular. Como se ha dicho, la alteración no se encontraría a nivel de la capacidad proliferativa de los linfocitos ni en la vía eferente del arco inmunologico. Podría postularse, en cambio, que el defecto reside en el transporte de la información antigénica $y / o$ en el proceso de reconocimiento del antígeno. Esto se basa en el hecho de que en nuestro estudio, en aquellos lactantes que fueron incapaces de sensibilizarse jnicialmente con DNCB, este test persistió negativo una vez recuperada la desnutrición, a pesar de la intensa reacción química local observada en el momento de la sensibilización (36). Este fenómeno, también observado por otros autores (38), estaria indicando una falta de memorización de la información.

Se ha sugerido que la depresión de la respuesta inmunitaria celular en el niño desnutrido podría deberse a un aumento de los niveles circulantes de corticoesteroides $(35,37,41)$. Esta elevación ha sido comunicada por varios autores, principalmente en pacientes con Kwashiorkor $(44,45)$. En cambio en pacientes con Marasmo, Ferreyra y cols. han encontrado niveles normales de cortisol circulante (46).

Es indudable que se requiere profundizar las investigaciones sobre los mecanismos inmunológicos que se alteran en la desnutrición. Alteraciones como Jas descritas en la inmunidad celular no sólo scrvirían para explicar la severidad de las infecciones en estos sujetos, sino que también tendrían importancia práctica como por ejemplo en programas de vacunación masiva en poblaciones en que la desnutrición es prevalente, ya que estos sujetos podrían sufrir fenómenos de interferencia que no hicieran enteramente efectivas las inmunizaciones.

\section{REFERENCIAS}

1.-Scrimshaw, N. S., Taylor, C. E. and Gordon, J. Interactions of nutrition and infection. Amer. $J$. Med. Sc. 237: 367, 1959. 
2.-Salombi, J. B., Maia, L. J. and Goidum, J. E. Malnutrition ind the common communicible $\mathrm{dj}$ seases of childhood in Rural Guatemala. A, J. P. H. 58: 505, 1968 .

3.-PAHO. Technical Group on Guildstimes for Foo: Fortification in Latin America and the Caribbean. PAHO Scient. Publ. No 240, 1972.

4.-Defunciones y Causis de Muerts. S. N. S. 1964. Santiago-Chile.

5.- Monckeberg, $F$. Algunos aspectos de la deshislratación aguda del lactante. Gazcta S: nitaria 20): 1. 1965 .

6.-Health Conditions in the Americas. 1961-1962. PAHO Scient. Publ. No 104.

7.-Brown, R. E. Pediatric post mortem survey in Uganda. Trop. Geogr. Med. 17: 289, 1965.

8.-Bergsma, D. and Good, R, A. Inmunologic Deficiency Discases in Man. Birth Defects Orisinal Alticle Series. Vol. IV, N' 1, 1968.

9.-Cood, R. A. if al. In: S. Mund, ed, Infections agents and host reactions. Saunders, Philadelphit, 1970.

10.-Scrmshaw, N.S. Protein deficiency and infective diseases. In Munro, H. N. and Allison, J. B. eds. Mammalian Proteiri Metabolism. Vol. II Academic. Press, 1964

11.-Dawson, C. E. and Blagg. W. Further studies on effect of human saliva on cholera vibrio in vitro.

J. Dent. Res. 29: 240, 1950.

12,- Kumare, J. Desnutrición e inmunología. En Ranus Galvín, R. Desnutrición en el niño, pp. 121. Impresiones Modernas, México, 1969.

13.-Trowell, II. C., Davies, J. N. P. and Didsi. R. F. A. "Kwashiorkor". Edward Arnold, London, 1954.

14.-Hernandez, J. F., Virquéz, A. V. y Kumule, J. Actividad fagucitatia y estado nutricional. Metibolismo y acción bactericida. XIX Reunión Reglamen. taria de la Asociación de Investigación pedítrica. A. C., 1969. México, D. F.

15.- Altay, C., Say, B., Dogramaci, N. and Buresol, A. Nitroblue lietrazolium test in chiluren with malnutrition. J. of Ped. 81: 392. 1972.

16.-Brown, R. E. and Katz, M. Antigenic stimulation in undernourished children E. Afr. Med. J, 42: 221,1965 .
17.-Keet, M. P. oid Thtm, H. Serure inmunoglobuliti in Kwashiorkor. Arch. Dis. Childf. 44: 600, 1969

18... Watsen, C. E. and Frow in protein-calorit-matnutrition. Art?. Dis Chithlth. 45: 282,1970

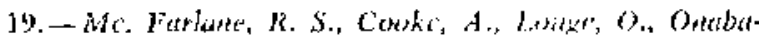
mire, M. O. and Houth. J. E. Inmuremglobulins. transferrín, cereriloplasmin and thetsophile antibodies in Kwashiorkor. Trup. (jars, Med., 22: 0 ]. 1970.

20.-- 7acher, J. J., Malenge, P., Massuryel, R., Thllet

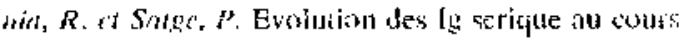
du Kunshiorkor. Riv. Fusop. Eutuder C.lin., et Riol. 1043, 1971.

21.--Najur, S. S., Siphar, M. and A.sour, R. Y S:fum levels of inmunombobulins in marasmic infarsu Arch. Dis. Chitdh. 44: 120, i964.

22.-Johassson, S. G. O.. Methis, 7 , and Vuldguist, $B$ Inmunuglobulin levels in Ethiopian pre-school chi] dren with special reference to high concentristion of innunoglobulin. E. Lancet I: 1118, 1968

23. -- A Survey of nutritiunal-inmunological julcras! ia:sis. Bull. Wld. Hlih. Ura. 4ty: 537, 1972.

24.-- Bndiansky, E. ef ata Siha, N. Formaça de anlicuerpos na distrolia pluriciuencial hidropogenica Hospital (Río de Janciro) 52: 251, 1957.

25.... Hetoriks, $\boldsymbol{P}$. J. and Villicrs, L. S. Antibody response in children with protein maluatrition. Ampr J. Clin. Nutr. 10: 379, 1962.

26.-Olarte, J, Cravisto, J. y Cumpos, B. Inmusidial er. el nin̆o atesnutrido. I Producción de antítoxina diftirica, Bol. Mest. Hosp. Inf. (Mex) 13: 467, 1956.

77.- Bron'n, R, F. and Katz. M. Failure of antibody

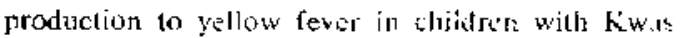
hiorkor. Trop. Geogr. Med. Is: I25. IMŕn.

2si---ffarimt, P. S. E. G. Tubereulin ratetions in mal nourished children. Lancet 2: 719, 1965.

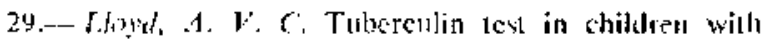
malnutrition. Brit. Meid, I, 3: 529. 1968.

30.--Hurtato. R. Alteración de ba inmuniorad sclular en lit desnutrición marismica nuedida a travis de lit conversión fuberculínicı. Rev. Chil. P'ed. 41: 997 1970 .

31...-Vinf, F, W. Post mortem findings in the native. of Kenya. E. Afr. Mod. J. 13; 332, 1937. 
32.-Warts, $r$. Thymus weights in malnourished children. J. Tron. Pediat. 15: 155, 1969.

33.- Chuaqui, B., Taucher, E., Pinto, C., Solimano, $G$. Desnutrición calórico-proteica en lactantes. Análisis de pesos alc órganos y caracteres histológicos. Pediatría 14: 127, 1971.

34.-Becker, W. B., Kipps, A. and Mc. Kenzie, D. Dissemiuated herpes simplex virus infection. Amer. J. Dis. Childh. 115: 1, 1968.

35.- Simythe, P. M., Schonland, $M$, Breretort-Stiles, $G$. G., Coovadit, H. M., Grace, H. J., Looning, $\boldsymbol{W}$. E. K., Mafoyanee, A., Parent, M. A., Vos, G. H. Thymolymphatic deficiency and depression of cellmediated immunity in protein-calorie maltnutrition. Lancet. 2: 939, 1971.

36.- Schlesinger, L., Stekel, $A$. Inpaired cellular immunity in marasmic infants, Am. y Clin. Nutr. En prensa.

37.-Chandra, R. K. Immunocompetence in undernu. trition. J. Pediat. 81: 1194, 1972.

38.-Fetelman, G. and Gianantunio, C. A. Aspectos inmunológicos de la desnutrición en el niño. Medicina $32: 1,1972$.

39.-Edelman, R., Suskind, R., Olson, R. E. and Siri. sinha, $S$. Mechanims of defective delayed cutaneous hypersensitivy in children with protein-calorie malnutrition. Lancet. 1: 516, 1973.
40.--Geolhaysen, J., Rosen, E. V., Katz, S., Ipp. T. and Metz, $f$. Impaired cellular immunity in Kwashiorkor with iraprocement after therapy. Br. Med. J. 4: 527,1971 .

41.-Lopez, V., Davis, S. D., and Smith, N. J. Studie; in Infantile Marasmus. IV Impairement of immunologic responses in the marasmic pig. Pediatric Res. 6: 779, 1972.

42.-Monckeberg, F. Adaptation to chronic calorie and protein restriction in infants. In Mc. Cance, $R$. A. and Widdowson, E. M. eds. Calorie deficiencies and protein deficiencies. J. \& A. Churchill L.td.

43.-Brow'n, $R$. E. and Katz, M. Passive transfer of delayed hypersensitivity reaction to tuberculin in chi]dren with proteeith calorie malnutrition. J. Pediat. 70: $126,1967$.

44.-A Weyne, G. A. O. and Young, V, H. Adrenocortical function in children with severe protein-calorie malnutrition. Clin. Sci, 33: 189, 1967.

45.-Rao, K. S. J., Srikuntia, S. G. and Gopalat, C. Plasma corticol levels in protein-calorie malnutrition. Arch. Dis. Childh. 43: 365, 1968.

46.- Ferreyra, E., Rivarola, A., and Beas, $F$. Adrenocortical reserve in infants with marasmic malnutrition. Comunicación personal. 